\title{
Article \\ Future Projection for Climate Suitability of Summer Maize in the North China Plain
}

\author{
Yanxi Zhao ${ }^{1,2,3(\mathbb{D}}$, Dengpan Xiao ${ }^{1,2,3, *}$ (), Huizi Bai ${ }^{3}$, Jianzhao Tang ${ }^{3}$ and Deli Liu ${ }^{4}(\mathbb{C})$ \\ 1 College of Geography Science, Hebei Normal University, Shijiazhuang 050024, China; 18233181223@163.com \\ 2 Hebei Laboratory of Environmental Evolution and Ecological Construction, Shijiazhuang 050024, China \\ 3 Engineering Technology Research Center, Geographic Information Development and Application of Hebei, \\ Institute of Geographical Science, Hebei Academy of Sciences, Shijiazhuang 050011, China; \\ baihz272@126.com (H.B.); tjzcau@163.com (J.T.) \\ 4 NSW Department of Primary Industries, Wagga Wagga Agricultural Institute, Wagga Wagga, NSW 2650, Australia; \\ de.li.liu@dpi.nsw.gov.au \\ * Correspondence: xiaodp@sjziam.ac.cn
}

Citation: Zhao, Y.; Xiao, D.; Bai, H.; Tang, J.; Liu, D. Future Projection for Climate Suitability of Summer Maize in the North China Plain. Agriculture 2022, 12, 348. https://doi.org/ 10.3390 /agriculture 12030348

Academic Editor: Claudia Di Bene

Received: 20 January 2022

Accepted: 27 February 2022

Published: 28 February 2022

Publisher's Note: MDPI stays neutral with regard to jurisdictional claims in published maps and institutional affiliations.

Copyright: (c) 2022 by the authors Licensee MDPI, Basel, Switzerland. This article is an open access article distributed under the terms and conditions of the Creative Commons Attribution (CC BY) license (https:// creativecommons.org/licenses/by/ $4.0 /)$.

\begin{abstract}
Climate change has and will continue to exert significant effects on social economy, natural environment, and human life. Research on the climatic suitability of crops is critical for mitigating and adapting to the negative impacts of climate change on crop production. In the study, we developed the climate suitability model of maize and investigated the climate suitability of summer maize during the base period (1981-2010) and two future periods of 2031-2060 (2040s) and 2071-2100 (2080s) in the North China Plain (NCP) based on BCC-CSM2-MR model (BCC) from the Coupled Model Comparison Program (CMIP6) under two Shared Socioeconomic Pathways (SSP) 245 and SSP585. The phenological shift of maize under future climate scenarios was simulated by the Agricultural Production Systems Simulator (APSIM). The results showed that the root mean square errors (RMSE) between observations and projections for sunshine suitability $\left(S_{S}\right)$, temperature suitability $\left(S_{T}\right)$, precipitation suitability $\left(S_{P}\right)$, and integrated climate suitability $\left(S_{Z}\right)$ during the whole growth period were $0.069,0.072,0.057$, and 0.040 , respectively. Overall, the BCC projections for climate suitability were in suitable consistency with the observations in the NCP. During 1981-2010, the $S_{P}, S_{T}$, and $S_{Z}$ were high in the north of the NCP and low in the south. The $S_{P}, S_{T}$ and $S_{Z}$ showed a downward trend under all the future climate scenarios in most areas of NCP while the $S_{S}$ increased. Therein, the change range of $S_{P}$ and $S_{S}$ was 0-0.1 under all the future climate scenarios. The $S_{T}$ declined by $0.1-0.2$ in the future except for the decrease of more than 0.3 under the SSP585 scenario in the 2080s. The decrease in $S_{Z}$ in the 2040s and 2080s under both SSP scenarios varied from 0 to 0.2. Moreover, the optimum area decreases greatly under future scenarios while the suitable area increases significantly. Adjusting sowing data (SD) would have essential impacts on climate suitability. To some extent, delaying SD was beneficial to improve the climate suitability of summer maize in the NCP, especially under the SSP585 scenario in the 2080s. Our findings can not only provide data support for summer maize production to adapt to climate change but also help to propose agricultural management measures to cope with future climate change.
\end{abstract}

Keywords: adaptation; climate change; summer maize; phenology shift; GCM

\section{Introduction}

Over the past 100 years, global warming has become more and more significant, and it has become one of the major issues affecting the sustainable development of human society [1]. Global warming has exerted a significant impact on the natural environment, social economy, and human life, among which the impact on agricultural production on which human survival depends has attracted widespread attention [2-9]. Generally, different crops have different demands for climate resources, and more or less, climate resources are not conducive to the normal growth and development of crops $[10,11]$. The quantity 
variation of key climatic factors (i.e., sunshine hours, temperature, and precipitation) can be transformed into the climate suitability of crop growth and development based on the membership function method in fuzzy mathematics [12,13]. Moreover, the crop climate suitability can play a role in predicting final yield [14,15]. The study of climate suitability not only helps to make specific divisions of regions according to climate conditions, e.g., unsuitable area (unsuitable area for crop growing), less suitable area (less suitable area for crop growing), suitable area (suitable area for crop growing) and optimum area (optimum area for crop growing) [16,17], but also can rationally plan the planting areas of crops [17-20]. Moreover, the climate suitability for different varieties of the crop is different. By comparing the climate suitability for three varieties of early maturity, medium maturity, and late maturity of spring soybean in North China, the medium maturity variety was the most suitable variety for planting [21]. The climate suitability model is a useful tool to investigate the sensitivity of crops to climatic factors such as temperature, precipitation, and sunshine, analyze the response mechanism of crops to climate change, and optimize the selection of crop varieties [22,23].

Climate change exerted an important impact on the crop growth process, and the study of future climate suitability is crucial for taking effective adaptive measures to cope with the adverse effects of climate change on crop production. Global climate model (GCM) is an effective tool to explore the mechanisms of climate change and predict future climate change, and the simulation results of GCMs can provide important data support to study the impacts of future climate change on agricultural production at different scales [24]. The World Climate Research Program (WCRP) initiated a new round of the International Coupled Model Comparison Program (CMIP6). Since the implementation of CMIP was more than 20 years, the number of participating models for CMIP6 was the largest, the scientific experiment design was the most complete, and the largest amount of model data was provided [25]. Compared with previous climate models such as CMIP5, the simulations of CMIP6 models for climate systems were closer to the observations and had less uncertainty, so the simulating ability of climate change has significantly improved [26,27]. For example, in terms of simulation for extreme climate at global scale, CMIP6 models had a general improvement in simulating the changing trend of extreme climate compared to CMIP5 models [28]. In the study, the BCC-CSM2-MR model (BCC) from CMIP6 was used to explore the crop climate suitability in the future. In contrast with the previous versions of the BCC model from CMIP5, the physical mechanism of BCC, such as atmospheric radiation and deep convection process, was improved to make it more suitable for the simulation of climate distribution [29-31].

Maize is an important food and feed crop in the world and has a considerable impact on agricultural economy [32]. In China, maize is one of three major food crops while it ranks first among miscellaneous grain crops, widely distributed in Northeast, North, Northwest, and Southwest China [33]. The North China Plain (NCP) is an important grain production base in China, with maize production accounting for more than $30 \%$ of the country's total output [34]. Over the past few decades, climate change has had a significant impact on maize production in the NCP [35]. From 1980 to 2009, the contribution of climate change to maize yield reduction in the NCP was 15-30\%, among which the contribution from the reduction in solar radiation was $12-24 \%$, and that from temperature increment was 3-9\% [36]. Therefore, It is of great significance to study the climate suitability of maize in the NCP and evaluate the impact of climate resources on agricultural production. The evaluation of agricultural climate suitability is beneficial to cope with the impact of climate change on maize production, rationally use agricultural climate resources, improve the agricultural management level and ensure agricultural production safety [14]. Tang and Liu [15] analyzed the spatial-temporal characteristics of maize climate suitability during the current period and future period in the NCP based on 30 CMIP5 GCMs. However, the phenology shift of maize in the above study was obtained by calculating the active accumulated temperature, with a lack of mechanism. During the historical period, the observed records of maize phenology at the agro-meteorological stations should be used for developing 
the climate suitability model. In addition, the crop model can be used to simulate crop growth under various environmental conditions and agricultural management measures. Therefore, this study took advantage of the crop model to simulate the future phenology of maize. The Agricultural Production Systems Simulator (APSIM) was selected to simulate the phenological shift of maize under future climate scenarios.

In the study, we mainly investigated the climate suitability of maize in the NCP under future climate scenarios on the basis of daily climate data of BCC from CMIP6 and future phenology conditions simulated by the APSIM model. The objectives of the study were (1) to develop the climate suitability model of maize based on the regional climatic conditions and fuzzy mathematics; (2) to analyze the spatial and temporal change characteristics of climate suitability for maize in the NCP under future scenarios; and (3) to evaluate the effect of adjusting sowing date on maize climate suitability.

\section{Materials and Methods}

\subsection{Study Area}

The NCP $\left(113.7-122.7^{\circ} \mathrm{E}, 32.9-40.5^{\circ} \mathrm{N}\right)$ is delimitated in the east by the sea, the west by Taihang Mountains, the south by the main stream of the Huaihe River, the north by the Yan Mountains, accounting for approximately $1.4 \times 10^{5} \mathrm{~km}^{2}$ of arable land (Figure 1) [37]. The region has a warm temperate monsoon climate with plenty of light and heat resources [37]. The mean annual temperature across the study area ranged from 9.6 to $16.0{ }^{\circ} \mathrm{C}$ in nearly fifty years [38]. The annual precipitation is not evenly distributed, with over $70 \%$ of precipitation appearing in July through September. The main soil type in the NCP is the loam of Aeolian origin, a soil type deposited by rivers over geological periods. The NCP is an important grain production region in China, where the main cropping system is the double-cropping systems of winter wheat-summer maize [36]. Summer maize is usually planted in middle June and harvested in September [39].

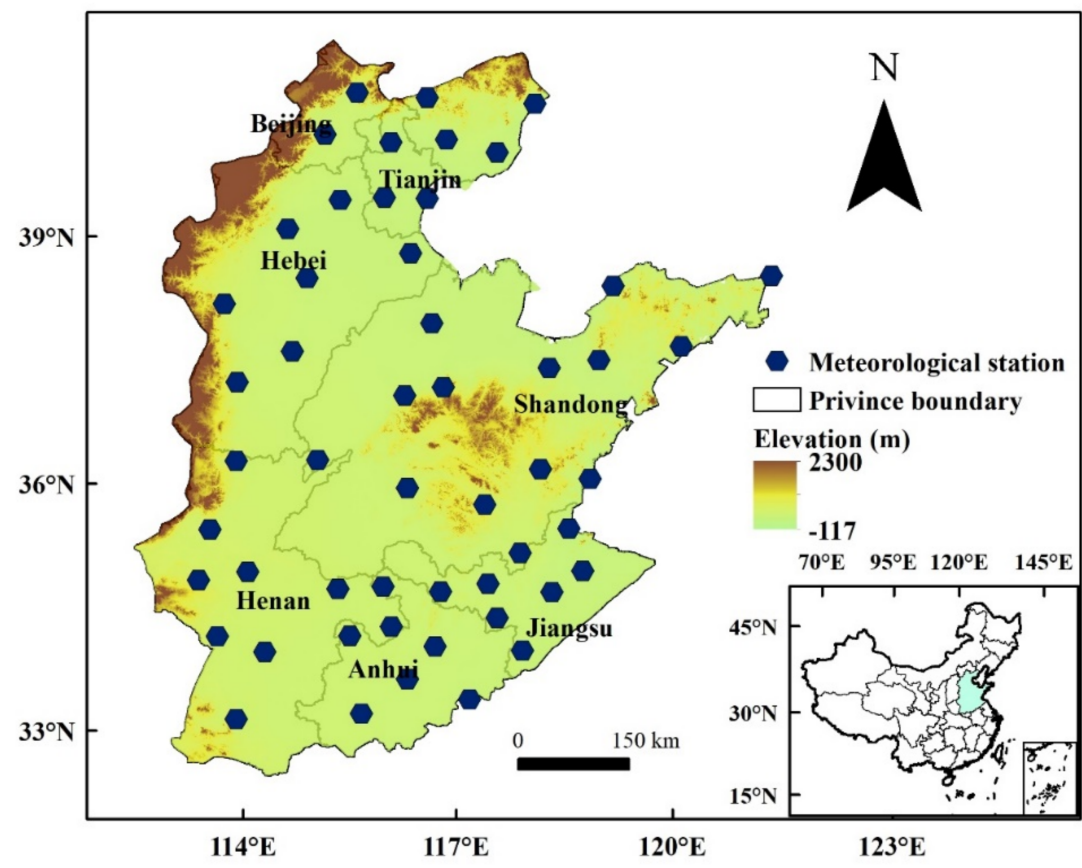

Figure 1. The spatial distribution of 52 meteorological stations in the North China Plain.

\subsection{Climate Data}

The historical records about daily climate data, including mean temperature (Tmean), maximum temperature (Tmax), minimum temperature (Tmin), precipitation (Prec), and sunshine hours (Sh) during 1981 to 2010 for 52 meteorological stations across the NCP, were obtained from China's Meteorological Administration (CMA). 
Future climate scenario data were obtained from GCMs, which is provided by the World Climate Research Program (WCRP) of Coupled Model Inter-comparison Project phase 6 (CMIP6, https: / / esgf-node.llnl.gov/search/cmip6/ (accessed on 20 February 2020)). CMIP6 integrated climate change information from the CMIP5 simulations of the representative concentration pathway (RCP) and future societal development pathways (SSPs) [40]. The SSPs describe alternative evolutions of future society under climate change and/or climate policy. SSPs 1 and 5 envision relatively optimistic trends for human development, with substantial investments in education and health, rapid economic growth, and wellfunctioning institutions [40]. However, SSP5 assumes an energy-intensive, fossil-based economy, while SSP1 assumes an increasing shift toward sustainable practices. Further details of the SSPs can be found in O'Neill et al. [40]. In our study, we focused on fossil-fueled development trends (i.e., SSP5) and the highest forcing pathway (i.e., RCP8.5, the radiative forcing of $8.5 \mathrm{~W} \mathrm{~m}^{-2}$ by 2100), defined by SSP5-85 (SSP585). Additionally, the combination of medium social vulnerability and medium radiative forcing, defined by SSP2-45 (SSP245), was also used for comparison. SSP245 is the updated RCP4.5 scenario, and the radiative forcing will stabilize at $4.5 \mathrm{~W} / \mathrm{m}^{2}$ in 2100. A GCM named BCC-CSM2-MR (BCC) under SSP245 and SSP585 with a time span of 2031-2060 (2040s) and 2071-2100 (2080s) developed by Beijing Climate Center, China, was selected. In the study, the 2040s under SSP245, 2080s under SSP245, 2040s under SSP585, and 2080s under SSP585 were defined as S1, S2, S3, and $S 4$, respectively.

The statistically downscaled method developed by Liu and Zuo [41] was used to generate daily climate data at each station from the monthly data of the BCC-CSM2-MR model (BCC). This method was mainly divided into two steps: spatial downscaling and temporal downscaling. The spatial downscaling was to transform monthly GCMs on the grid scale into monthly stations data using the inverse distance-weighted interpolation (IDW). The formula is as follows:

$$
S_{i}=\sum_{k=1}^{4}\left[\frac{1}{d_{i, k}^{m}}\left(\sum_{j=1}^{4} \frac{1}{d_{i, j}^{m}}\right)^{-1} P_{k}\right]
$$

where $S_{i}$ is the downscaled site-specific GCMs projection at site $i, P_{k}$ is the GCMs projection at cell $\mathrm{k}, d_{i, k}\left(d_{i, j}\right)$ is the distance between site $i$ and the center of cell $k(j), m$ is the control parameter.

In the spatial downscaling process, the qq-mapping bias correction method was applied to correct the bias of the spatial downscaling data to match with the observations. The bias-corrected spatial downscaling data were calculated by

$$
x_{k}^{f}=y_{i}^{o}+\frac{y_{i+1}^{o}-y_{i}^{o}}{x_{i+1}^{h}-x_{i}^{h}}\left(x_{k}^{r}-x_{i}^{h}\right), x_{i}^{h} \leq x_{k}^{r} \leq x_{i+1}^{h}
$$

where $x_{k}^{f}$ is the bias-corrected spatial downscaling data, $k=1,2, \ldots, n, y_{i}^{o}$ is the monthly observed data in the baseline period, $x_{i}^{h}$ is the GCMs monthly data in the baseline period, $x_{k}^{r}$ is the future GCMs projected data before bias correction.

Then the spatial downscaling monthly climate data for each station was transformed to daily climate data using a modified stochastic weather generator (WGEN) [42].

\subsection{Phenology Data and Future Phenology Simulation}

The observed data of maize phenology, including sowing data (SD), flowering data (FD), and maturity data (MD) for 49 agro-meteorological stations across the NCP during 1981-2010, were obtained from China's Meteorological Administration (CMA). To investigate the climate suitability of maize at different growth periods, the whole growth period (WGP) was divided into two periods: vegetative growth period from SD to FD (VGP) and reproductive growth period from FD to MD (RGP). The phenology data of the adjacent agro-meteorological stations were used to calculate climate suitability for the three meteo- 
rological stations without phenology data. With future climate change, the phenology of maize across the NCP will also change. In order to more accurately calculate the climate suitability under future climate scenarios, the APSIM, which is a comprehensive model developed to simulate biophysical processes in agricultural systems [43,44], was selected to simulate the maize phenology under future climate scenarios. Generally, the APSIM model can provide an acceptable prediction of crop productivity under the combined influences of climate change, soil condition, and management measures and was widely used in agricultural research [36,45-48]. The APSIM model had been calibrated and validated based on observed phenological data for the selected stations in the previous study [49]. In addition, SD adjustments were considered in the validated APSIM model to simulate the maize phenology shift under future climate scenarios. A total of 5 sowing dates were set up, including observed SD during the historical period (S_Base), observed SD advanced by 30 days (S_A30) and 15 days (S_A15), and observed SD delayed by 15 days (S_D15) and 30 days (S_D30). The results can be used to evaluate the impacts of adjusting SD on the phenology and climate suitability of maize.

\subsection{Climate Suitability Model}

To characterize the climatic adaptability of maize to key climatic factors (i.e., sunshine hours, temperature, and precipitation) and integrated climatic conditions in the NCP, the climate suitability model was built with reference to related studies [12,50-52].

\subsubsection{Sunshine Suitability $\left(S_{S}\right)$ Model}

The sunshine hours had a great influence on the growth and development of crops. The $S_{S}$ of maize was calculated as follows [23,52,53]:

$$
S_{S}=\left\{\begin{array}{c}
e^{-\left[\left(S_{i}-S_{0}\right) / r\right]^{2}} S_{i}<S_{0} \\
1 S_{i} \geq S_{0}
\end{array}\right.
$$

where $S_{0}$ is the daily sunshine hours when the percentage of daily sunshine hours reaches $70 \% ; S_{i}$ is daily sunshine hours $(\mathrm{h}) ; r$ is a constant that can be determined according to the climatic conditions across the NCP and relevant studies [52,54]. The values for $r$ at different growth periods are shown in Table $1 . S_{S}$ at the VGP, RGP, and WGP are referred to as $S_{S_{-} V G P}, S_{S_{-} R G P}$, and $S_{S_{-} W G P}$, respectively.

Table 1. Values of related parameters for calculating the suitability of sunshine, temperature, and precipitation in vegetative growth period (VGP) and reproductive growth period (RGP) of summer maize.

\begin{tabular}{ccc}
\hline Parameters & VGP & RGP \\
\hline$r$ & 5.01 & 5.19 \\
$T_{1}$ & 20 & 10 \\
$T_{0}$ & 25 & 22 \\
$T_{2}$ & 35 & 32 \\
$K c$ & 0.7 & 0.9 \\
\hline
\end{tabular}

\subsubsection{Temperature Suitability $\left(S_{T}\right)$ Model}

$S_{T}$ is related to three base point temperatures at different growth periods of crops. Three basis point temperatures include the optimal temperature, lower limit temperature, and upper limit temperature of the crop life process. Under the optimal temperature, crops grow quickly and well, while crops cease to grow and develop above upper limit temperature or below lower limit temperature [23]. The $S_{T}$ of maize was calculated as follows $[23,52,53]$ :

$$
S_{T}=\frac{\left[\left(T_{i}-T_{1}\right)\left(T_{2}-T_{i}\right)^{B}\right]}{\left[\left(T_{0}-T_{1}\right)\left(T_{2}-T_{0}\right)^{B}\right]}
$$




$$
\text { Among }\left\{B=\frac{\left(T_{2}-T_{0}\right)}{\left(T_{0}-T_{1}\right)}\right\}
$$

where $T_{i}$ is daily mean temperature $\left({ }^{\circ} \mathrm{C}\right) ; T_{0}$ is the optimal temperature $\left({ }^{\circ} \mathrm{C}\right)$ at different growth periods; $T_{1}$ and $T_{2}$ is the lower limit temperature $\left({ }^{\circ} \mathrm{C}\right)$ and the upper limit temperature $\left({ }^{\circ} \mathrm{C}\right)$ during various growth periods. The specific values of $T_{0}, T_{1}$, and $T_{2}$ refer to the climatic conditions across the NCP and relevant studies $[50,52,55]$ and are shown in Table 1 . The $S_{T}$ during the VGP, RGP and WGP were defined by $S_{T_{-} V G P}, S_{T_{-} R G P}$, and $S_{T_{-} W G P}$, respectively.

\subsubsection{Precipitation Suitability $\left(S_{P}\right)$ Model}

It is very important for crop growth if precipitation can match the physiological water requirement of crops. $S_{P}$ was defined as the ratio of precipitation to physiological water requirement when precipitation is less or greater than physiological water requirement during the crop growth period. The $S_{P}$ of maize is calculated as follows [51]:

$$
S_{P}=\left\{\begin{array}{c}
R / R_{0} R_{i}<R_{0} \\
R_{0} / R R_{i} \geq R_{0}
\end{array}\right.
$$

where $R$ is precipitation $(\mathrm{mm}) ; R_{0}$ is the physiological water requirement of crops, which can be calculated as follows:

$$
R_{0}=K c \cdot E T_{0}
$$

where $K c$ is the crop coefficient and $E T_{0}$ is the reference crop evapotranspiration (mm). The $K c$ values of maize during various growth stages were determined according to relevant studies [56,57] and listed in Table 1 . The $E T_{0}$ values of maize are calculated based on the Penman-Monteith formula [57].

$$
E T_{0}=\frac{0.408 \Delta\left(R_{n}-G\right)+\gamma \frac{900}{T+273} U_{2}\left(e_{s}-e_{a}\right)}{\Delta+\gamma\left(1+0.34 U_{2}\right)}
$$

where $\Delta$ is the slope on the saturation vapor pressure temperature curve $\left(\mathrm{kPa}^{\circ} \mathrm{C}^{-1}\right)$; $T$ is the daily mean temperature $\left({ }^{\circ} \mathrm{C}\right) ; R_{n}$ represents net radiation $\left(\mathrm{MJ} \cdot \mathrm{m}^{-2} \cdot \mathrm{d}^{-1}\right) ; G$ is the soil heat flux $\left(\mathrm{MJ} \mathrm{m}^{-2} \mathrm{~d}^{-1}\right) ; \gamma$ is the hygrometer constant $\left(\mathrm{kPa}^{\circ} \mathrm{C}^{-1}\right) ; U_{2}$ is the wind speed $2 \mathrm{~m}$ above the ground $\left(\mathrm{m} \mathrm{s}^{-1}\right) ; e_{s}$ and $e_{a}$ are respectively the saturated vapor pressure and the actual vapor pressure $(\mathrm{kPa})$ at temperature $T$. The $S_{P}$ at the VGP, RGP and WGP were defined by $S_{P_{-} V G P}, S_{P_{-} R G P}$, and $S_{P_{-} W G P}$, respectively.

\subsubsection{Crop Climate Suitability during Different Crop Growth Stages}

The sunshine and temperature suitability during different growth stages are calculated by the arithmetical average method according to the following formula:

$$
\mathrm{S}_{c}=\frac{1}{m} \sum_{i}^{m} \mathrm{~S}_{c i}
$$

where $S_{c}$ represents $S_{S}\left(S_{T}\right)$ at different growth stages of maize; $I$ is the corresponding day sequence at each growth stage; $S_{c i}$ is the $S_{S}\left(S_{T}\right)$ suitability of $i$ day; $m$ is the total number of days at the corresponding growth stage.

\subsubsection{Integrated Climate Suitability $\left(S_{Z}\right)$ Model}

Crop growth and development are jointly affected by sunshine, temperature, and precipitation together. $S_{S}, S_{T}$, and $S_{P}$ can only reflect the influence of a single climatic factor on crop growth. Therefore, $S_{Z}$ is developed to make a comprehensive reflection of the impact of sunshine, temperature, and precipitation on maize growth and development. The formula is as follows:

$$
S_{Z}=a S_{S}+b S_{T}+c S_{R}
$$


Based on related studies and characteristics of crop growth and development in the NCP $[50,52,58]$, the coefficients $a, b$, and $c$ are taken as values $0.20,0.32$, and 0.48 , respectively in this study. The $S_{Z}$ during the VGP, RGP, and WGP were defined by $S_{Z_{-} V G P}, S_{Z_{-} R G P}$, and $S_{Z_{-} W G P}$, respectively.

\subsection{Spatial Interpolation}

In the study, the inverse distance weighting (IDW) in ArcGIS 10.3 was used to map the spatial distribution characteristics and to analyze spatial variation trends of $S_{S}, S_{T}, S_{P}$, and $S_{Z}$ during the 2040s and 2080s compared with the baseline period (1981-2010) in the NCP.

\section{Results}

3.1. Comparison between Observations and Simulations for Climate Suitability during 1981-2010

In the study, it can be found from Figure 2 that the Pearson correlation coefficient $(R)$ calculated between observations and projections for $S_{S}, S_{T}, S_{P}$, and $S_{Z}$ at different stages ranged from 0.10 to 0.46 . Meantime, the root mean square error (RMSE) calculated between observations and projections for $S_{S}, S_{T}, S_{P}$, and $S_{Z}$ at different stages was relatively small. In detail, the $R M S E$ of $S_{S_{-} W G P}, S_{T_{-} W G P}, S_{P_{-} W G P}$, and $S_{Z_{-} W G P}$ was $0.069,0.072,0.057$, and 0.040 , respectively. There was small uncertainty for the BCC projection in the interannual variation during 1981-2010, which can reasonably reproduce the temporal variation trend of the observed climate suitability. As was shown in Figure 2, the BCC projection displayed similar trends of observations for climate suitability. These results showed that the BCC projections for climate suitability were in suitable consistency with the observations and suitable for the assessment and prediction of climate suitability in the NCP.
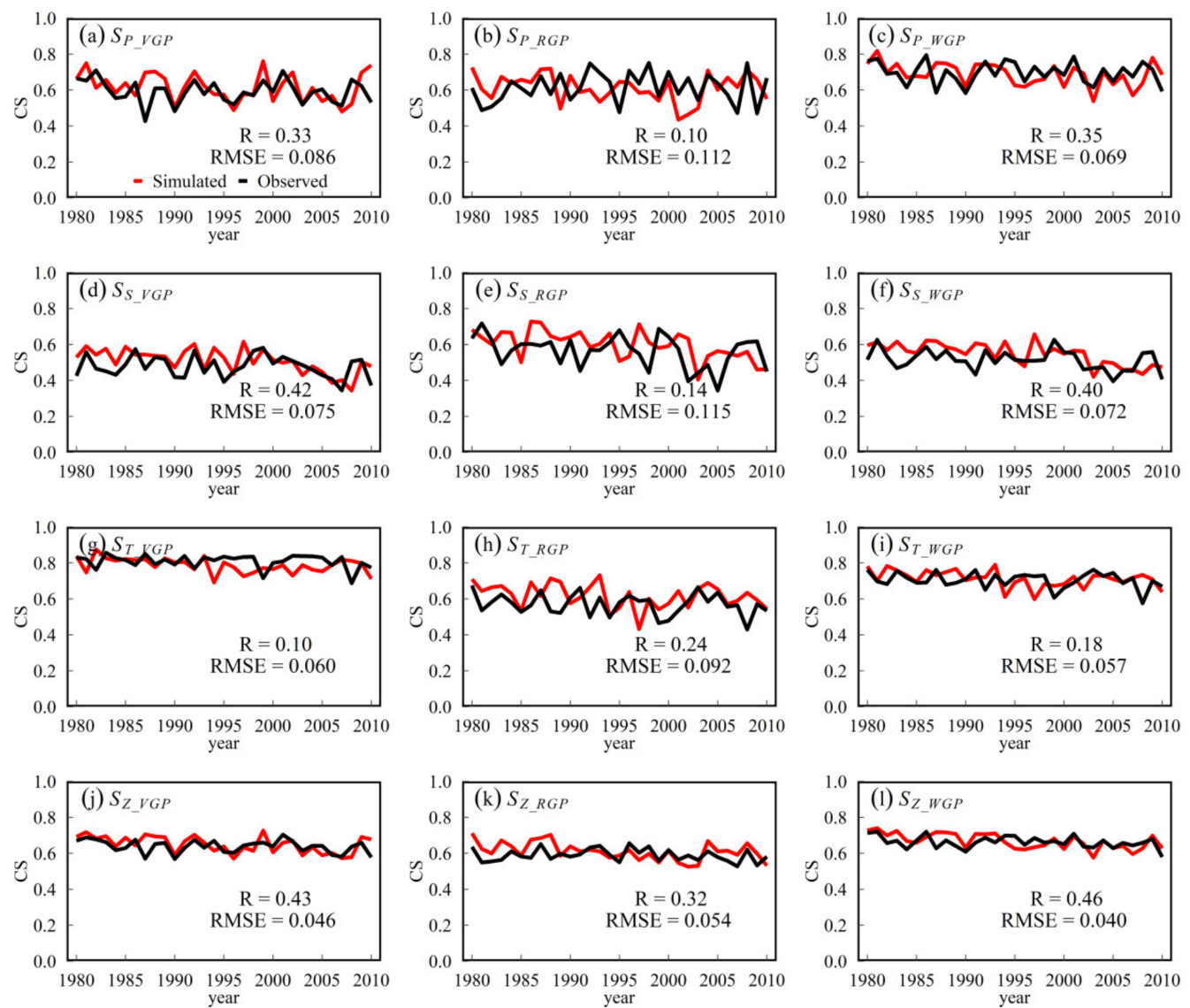

Figure 2. Observed and simulated maize climate suitability for the vegetative growth period $(\mathbf{a}, \mathbf{d}, \mathbf{g}, \mathbf{j})$, reproductive growth period $(\mathbf{b}, \mathbf{e}, \mathbf{h}, \mathbf{k})$ and whole growth period $(\mathbf{c}, \mathbf{f}, \mathbf{i}, \mathbf{l})$ during $1981-2010$ across the North China Plain. 


\subsection{Temporal Changes of Climate Suitability under the Future Climate Scenarios}

The changes of BCC projected $S_{S}, S_{T}, S_{P}$, and $S_{Z}$ in the 2040s and 2080s under SSP245 and SSP585 compared to the baseline period of 1981-2010 are shown in Figure 3.
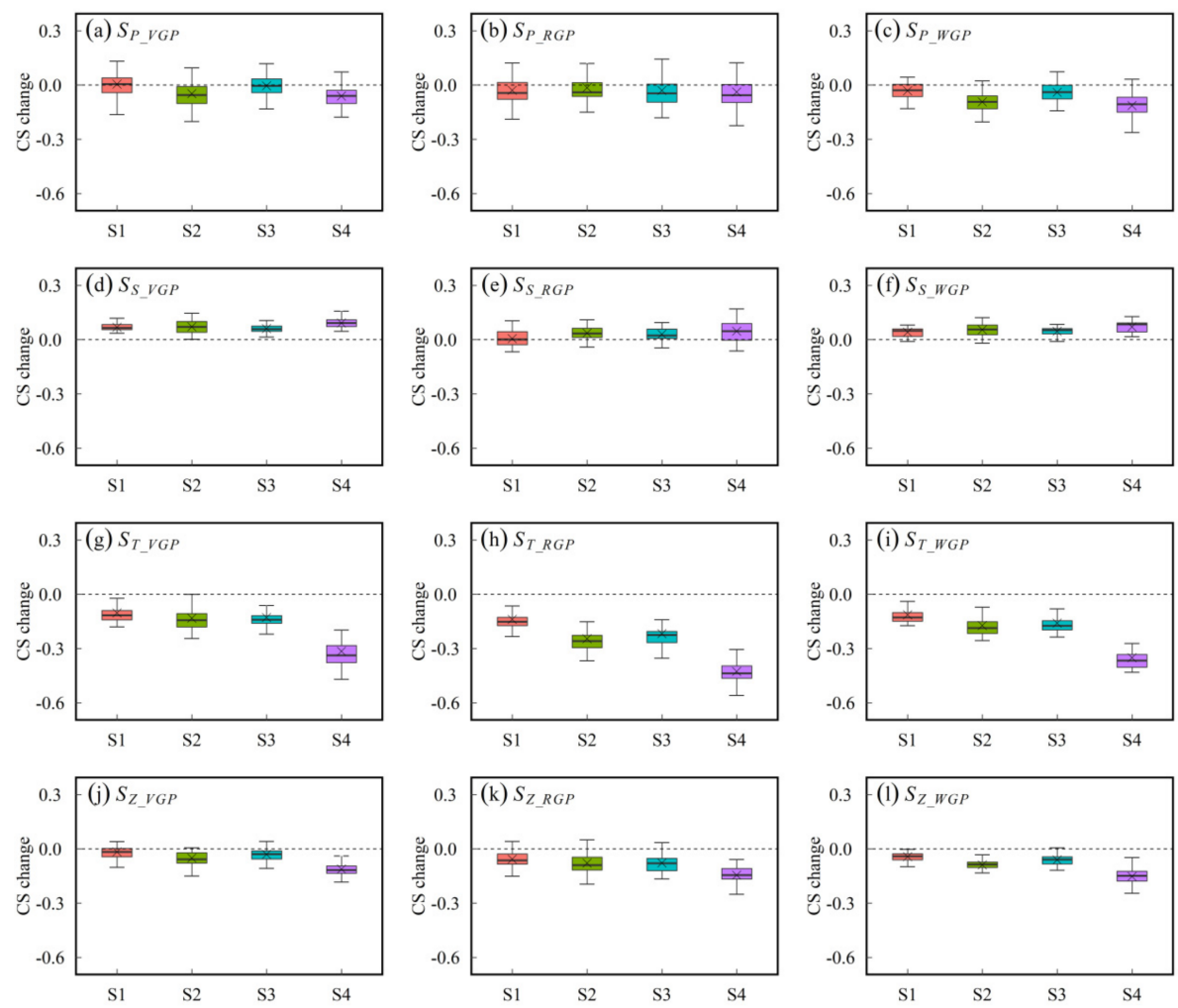

Figure 3. Changes in projected maize climate suitability for the vegetative growth period $(\mathbf{a}, \mathbf{d}, \mathbf{g}, \mathbf{j})$, reproductive growth period $(\mathbf{b}, \mathbf{e}, \mathbf{h}, \mathbf{k})$ and whole growth period $(\mathbf{c}, \mathbf{f}, \mathbf{i}, \mathbf{l}, \mathbf{l})$ during the 2040s and 2080s compared to 1981-2010 (S1, S2, S3, and S4 are the SSP245_2040s, SSP245_2080s, SSP585_2040s, and SSP585_2080s).

The change of BCC projected $S_{P_{-} V G P}$ under both scenarios in the 2040s compared to the baseline period was small (less than 0.01), while the decrease in BCC projected $S_{P_{-} V G P}$ in the 2080s was from 0.05 to 0.06 (Figure 3a). $S_{P} R G P$ in the 2040s and 2080s showed a uniform downward trend, and the range of decrease was 0.02-0.04 (Figure 3b). On the whole, the decline of $S_{P_{-} W G P}$ in the future compared to the baseline period was even more pronounced. The $S_{P_{-} W G P}$ under both scenarios in the 2040s decreased by $0.03-0.04$, and the decline of $S_{P_{-} W G P}$ in the 2080s was up to 0.09-0.11 (Figure 3c).

The increase in BCC projected $S_{S_{-} V G P}$ under both scenarios during the 2040s and 2080s compared to the baseline period was from 0.06 to 0.09 (Figure 3d). The increase in BCC projected $S_{S_{-} R G P}$ was relatively small, less than 0.05 (Figure $3 e$ ). The overall rise of $S_{S_{-} W G P}$ for the future periods under SSP245 and SSP585 was 0.04-0.07 (Figure 3f). The change of $S_{S}$ in the future across the NCP represented a slight increasing trend.

The decrease in $S_{T_{-} V G P}, S_{T_{-} R G P}$ and $S_{T_{-} W G P}$ during the SSP245_2040s, SSP245_2080s and SSP585_2040s ranged from 0.1 to 0.3 , while the decline of $S_{T_{-} V G P}, S_{T_{-} R G P}$ and $S_{T_{-} W G P}$ in the SSP585_2080s was between 0.3 and 0.5 (Figure 3g-i). The downtrend of the $S_{T}$ during the 2040s and 2080s across the NCP was significant, especially under SSP585_2080s.

The $S_{Z}$ was affected by sunshine, temperature, and precipitation together. The variation trend of $S_{Z}$ for the future across the NCP was consistent with the $S_{T}$, while the magnitude of decrease for the $S_{Z}$ was smaller than the $S_{T}$ on account of the $S_{S}$ and the $S_{P}$. The decline of $S_{Z_{-} V G P}, S_{Z_{-} R G P}$, and $S_{Z_{-} W G P}$ during the SSP245_2040s, SSP245_2080s, and SSP585_2040s was less than 0.1, and the $S_{Z_{-} V G P}, S_{Z_{-} R G P}$, and $S_{Z_{-} W G P}$ in the SSP585_2080s decreased by $0.1-0.2$ (Figure $3 j-1$ ). 


\subsection{Spatial Distribution of Climate Suitability in the Baseline Period (1981-2010) and Future Periods (2040s and 2080s)}

The spatial distribution of the $S_{S}, S_{T}, S_{P}$ and $S_{Z}$ during the baseline period (1981-2010) in the NCP is shown in Figure 4. $S_{P_{-} V G P}$ in the northwest of the NCP was higher than 0.6, while $S_{P} V_{V G P}$ in the southeast of the NCP was lower than 0.6 (Figure $4 \mathrm{a}$ ). There were most areas of the NCP with $S_{P} R_{G P}$ higher than 0.6 (Figure $4 \mathrm{~b}$ ). The areas with $S_{P} W_{G P}$ lower than 0.7 were distributed in the southeast of the NCP, and $S_{P \_W G P}$ in the northwest of the NCP exceeded 0.7 (Figure 4c). The spatial difference of $S_{S}$ across the NCP was relatively small. The values of $S_{S_{-} V G P}, S_{S_{-} R G P}$, and $S_{S_{-} W G P}$ during 1981-2010 in most areas of the NCP ranged from 0.4 to 0.6 (Figure $4 \mathrm{~d}-\mathrm{f}$ ). The spatial distribution of $S_{T}$ across the NCP was low in the south and high in the north. The ranges of $S_{T_{-} V G P}, S_{T_{-} R G P}$, and $S_{T_{-} W G P}$ in Hebei and Shandong during 1981-2010 were 0.8-0.9, 0.6-0.7, and 0.7-0.8, respectively, while the values of $S_{T_{-} V G P}, S_{T_{-} R G P}$, and $S_{T_{-} W G P}$ in the south of the NCP were less than the values in the north (Figure $4 \mathrm{~g}-\mathrm{i}$ ). There was a spatial characteristic with high in the north and low in the south for the $S_{Z}$. $S_{Z_{-} V G P}$ and $S_{Z_{-} W G P}$ in most areas were higher than 0.6 , and the values of $S_{Z_{-} R G P}$ ranged from 0.5 to 0.7 (Figure $4 \mathrm{j}-1$ ).
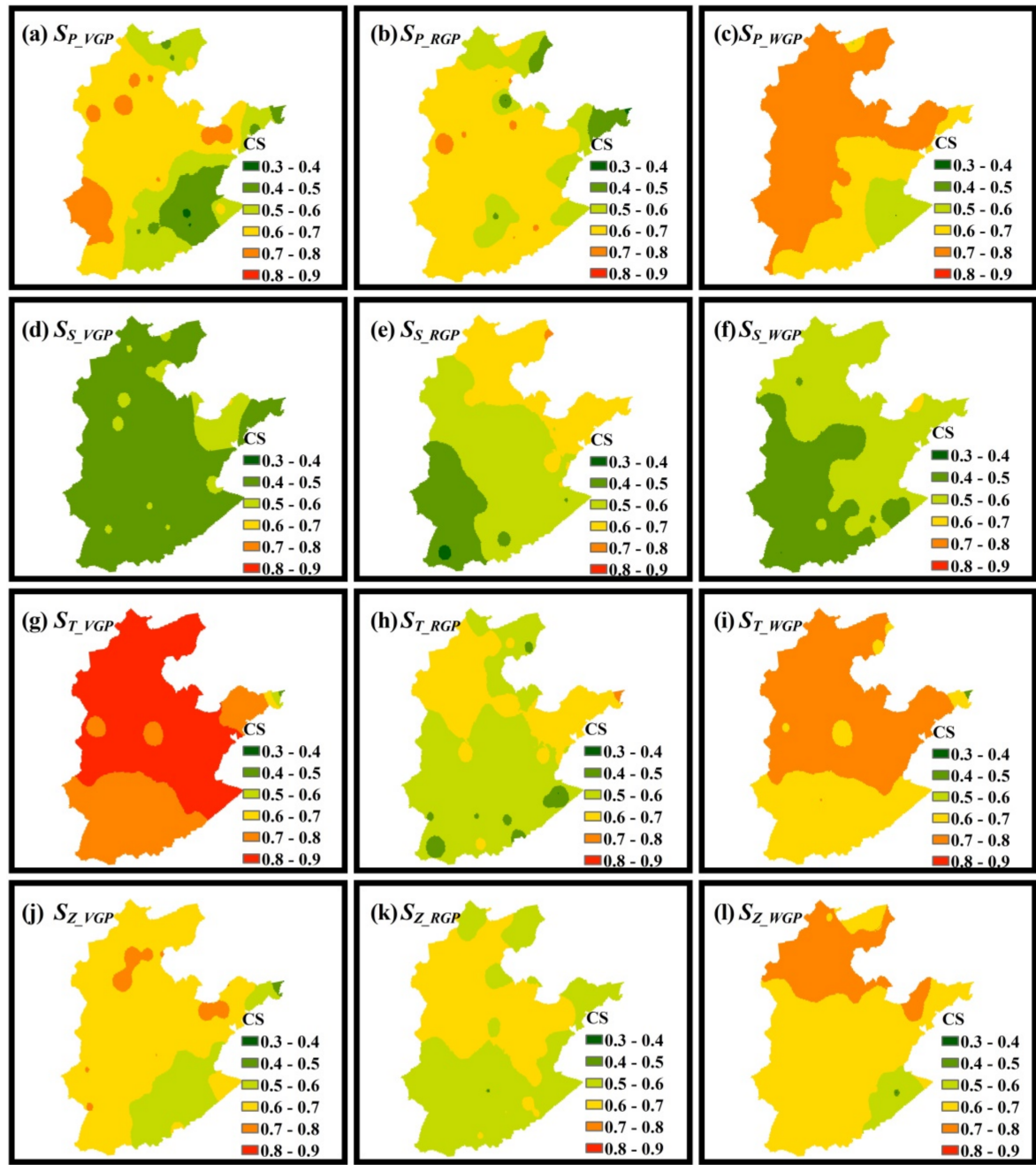

Figure 4. The spatial distribution of maize climate suitability for the vegetative growth period $(\mathbf{a}, \mathbf{d}, \mathbf{g}, \mathbf{j})$, reproductive growth period $(\mathbf{b}, \mathbf{e}, \mathbf{h}, \mathbf{k})$ and whole growth period $(\mathbf{c}, \mathbf{f}, \mathbf{i}, \mathbf{l})$ during the baseline period (1981-2010) in the North China Plain.

The spatial change characteristics of climate suitability in the NCP under the SSP245 scenario during the 2040s and 2080s are shown in Figures S1 and S2. Relative to the baseline period, $S_{P_{-} V G P}$ increased by $0-0.1$ in the central region of the NCP during the 2040s and 
2080s (Figures S1a and S2a). The areas with $S_{P_{-} R G P}$ and $S_{P \_W G P}$ decreasing by $0-0.1$ were distributed in most areas of the NCP for two future periods (Figures S1b-c and S2b-c). The $S_{S}$ increased by $0-0.1$ at most parts of the NCP except $S_{S_{-} R G P}$ in the 2040s (Figures S1d-f and S2d-f). In contrast to the $S_{S}$, the $S_{T}$ mainly presented a spatial characteristic of decline with a magnitude over 0.1 across the NCP in the 2040s and 2080s, particularly the decreasing amplitude of $S_{T \_ \text {RGP }}$ during 2080s exceeding 0.2 (Figures S1g-i and S2g-i). Similar to the $S_{T}$, there was a spatial characteristic of decreasing for the $S_{Z}$ in most parts of the NCP. However, the extent of decline for the $S_{Z}$ was significantly smaller than that of the $S_{T}$ (Figures $51 j-1$ and S2j-1).

The spatial change characteristics of climate suitability in the NCP under the SSP585 scenario in the 2040s and 2080s are presented in Figures 5 and 6. Compared to the baseline period, the spatial change characteristic of $S_{P}$ under the SSP585 scenario coincided with that under the SSP245 scenario. In addition, the decline for $S_{P} W G P$ in the north of the NCP during the 2080s surpassed 0.1 (Figures $5 \mathrm{a}-\mathrm{c}$ and $6 \mathrm{a}-\mathrm{c}$ ). The $S_{S}$ increased by $0-0.1$ at most parts of the NCP, while the increase in $S_{S}$ in the south of the NCP exceeded 0.1 (Figures $5 \mathrm{~d}-\mathrm{f}$ and $6 \mathrm{~d}-\mathrm{f}$ ). The decreasing trend of $S_{T}$ under the SSP585 scenario was more significant than that under the SSP245 scenario. The $S_{T}$ decreased by $0.1-0.3$ during the 2040s across the NCP (Figure 5g-i). Furthermore, the magnitude of decline was over 0.3 during the 2080s (Figure $6 \mathrm{~g}-\mathrm{i}$ ). The change characteristic of $S_{Z}$ under SSP585 in the 2040s was consistent with that of $S_{Z}$ under SSP245 in the 2040s and 2080s, with a decrease of $0-0.1$ (Figure $5 j-1$ ). The range of decline for the $S_{Z}$ under SSP585 in the 2080s was up to $0.1-0.2$ (Figure 6j-1).

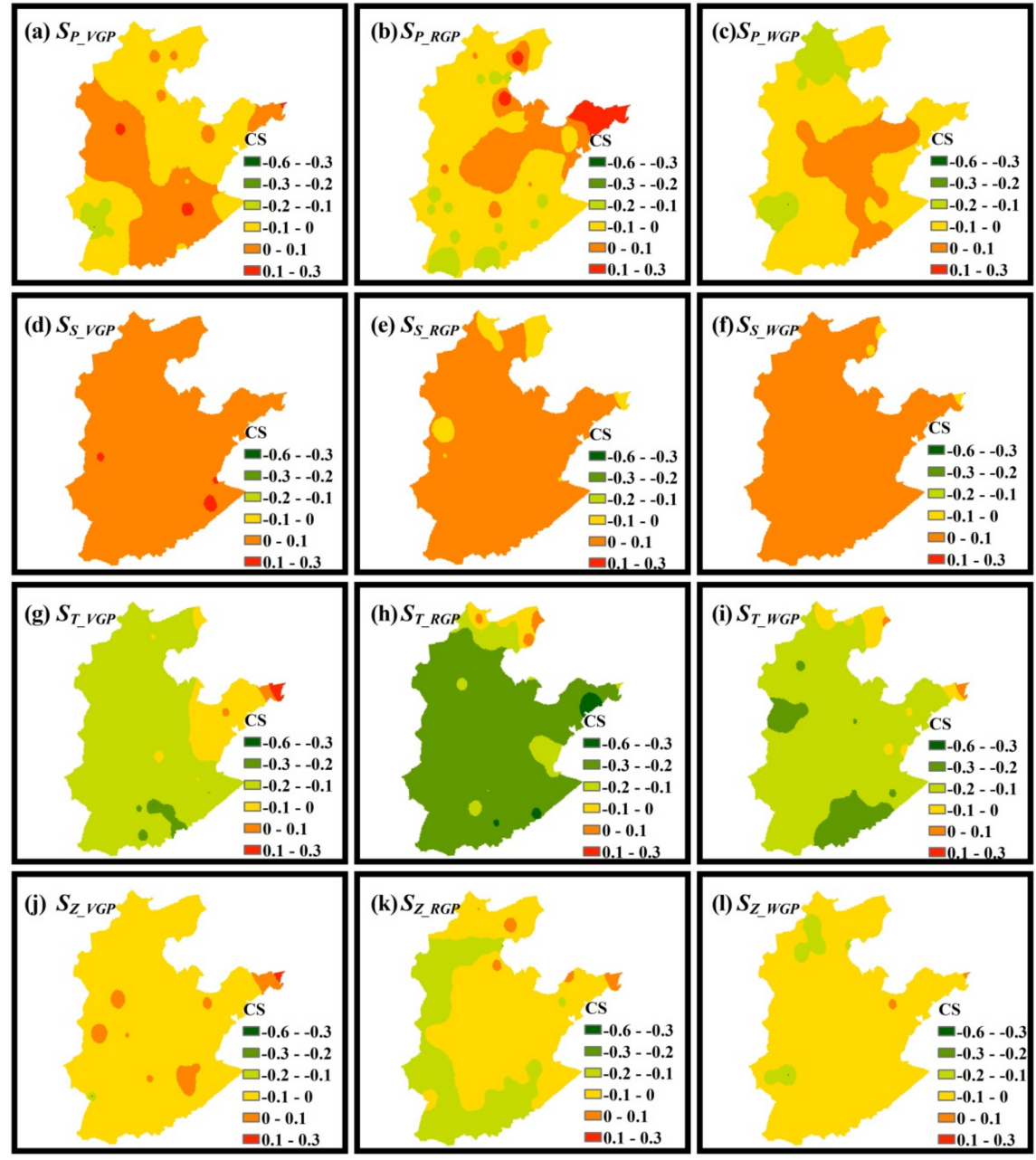

Figure 5. The spatial distribution of the change of maize climate suitability for the vegetative growth period $(\mathbf{a}, \mathbf{d}, \mathbf{g}, \mathbf{j})$, reproductive growth period $(\mathbf{b}, \mathbf{e}, \mathbf{h}, \mathbf{k})$ and whole growth period $(\mathbf{c}, \mathbf{f}, \mathbf{i}, \mathbf{l})$ under SSP585 during the 2040s compared to the baseline period (1981-2010) in the North China Plain. 

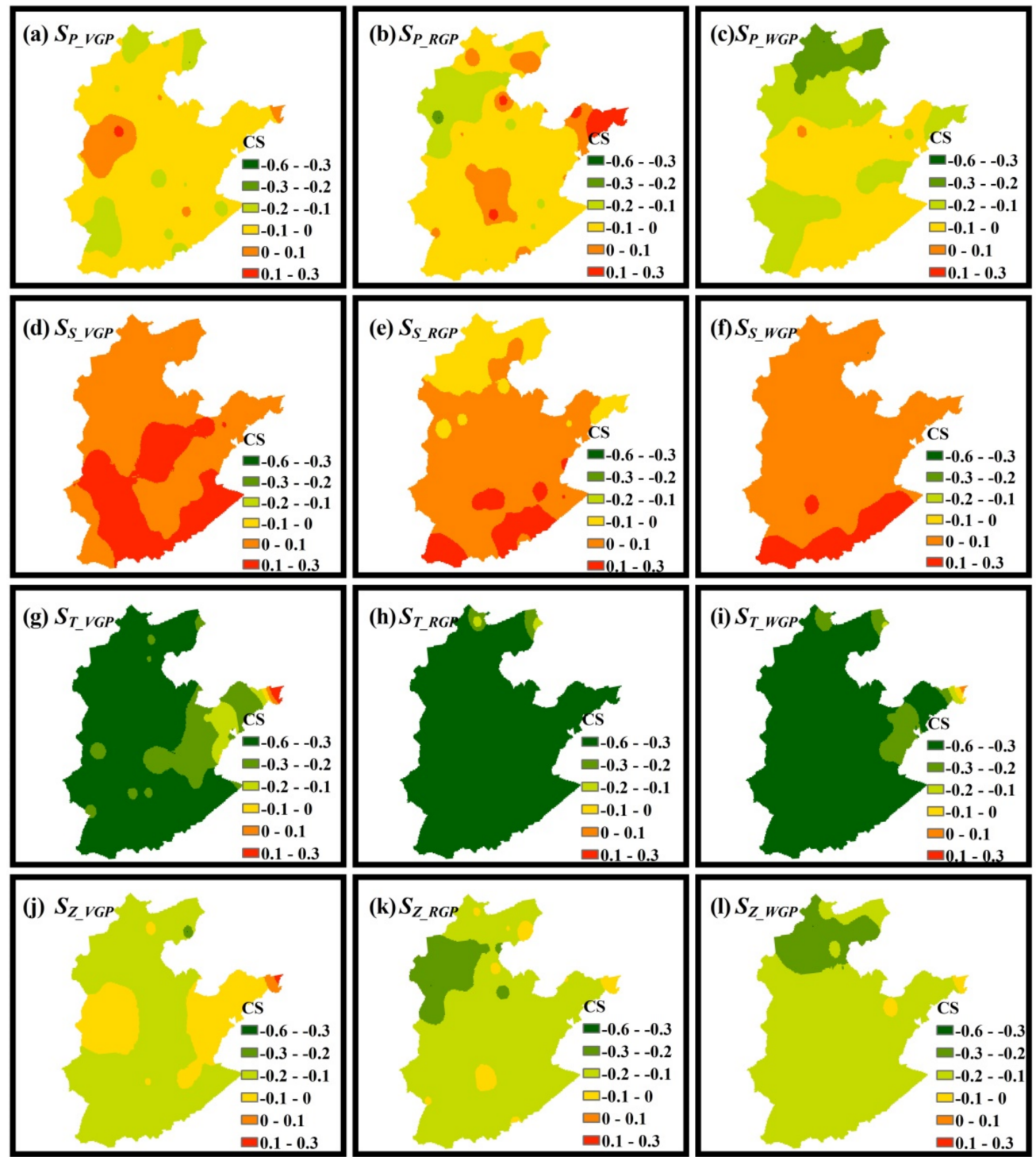

Figure 6. The spatial distribution of change of maize climate suitability for the vegetative growth period $(\mathbf{a}, \mathbf{d}, \mathbf{g}, \mathbf{j})$, reproductive growth period $(\mathbf{b}, \mathbf{e}, \mathbf{h}, \mathbf{k})$ and whole growth period $(\mathbf{c}, \mathbf{f}, \mathbf{i}, \mathbf{l})$ under SSP585 during the 2080s compared to the baseline period (1981-2010) in the North China Plain.

\subsection{Regional Division of Climate Suitability for Maize in the Baseline Period (1981-2010) and Future Periods (2040s and 2080s)}

According to the statistical principle and referring to the expression of possibility in the fourth assessment report of the Intergovernmental Panel on Climate Change (IPCC), the climate suitability of maize planting area was set as four grades: unsuitable area (CS $<0.05$, unsuitable area for maize growing), less suitable area $(0.05 \leq \mathrm{CS}<0.33$, less suitable area for maize growing), suitable area $(0.33 \leq \mathrm{CS}<0.66$, suitable area for maize growing) and optimum area (CS $\geq 0.66$, optimum area for maize growing) [16,17].

The regional division of climate suitability for maize during the baseline period (1981-2010) in the NCP is shown in Figure 7a. As an important maize production base in China, the climate in the NCP was generally conducive to the growth of maize. The optimum area and the suitable area accounted for about $50 \%$, respectively. The optimum area is distributed in the north of the NCP, and the suitable area is mainly distributed in the south (Figure 7a). This is similar to the research results of He and Zhou [17]. The regional division of climate suitability for maize under four future scenarios in the NCP is shown in Figure $7 \mathrm{~b}-\mathrm{e}$. With future climate warming, the overall climate suitability in the NCP shows 
a downward trend. The optimum area will decrease greatly under four future scenarios in the NCP, while the suitable area will increase significantly (Figure 7b-e).

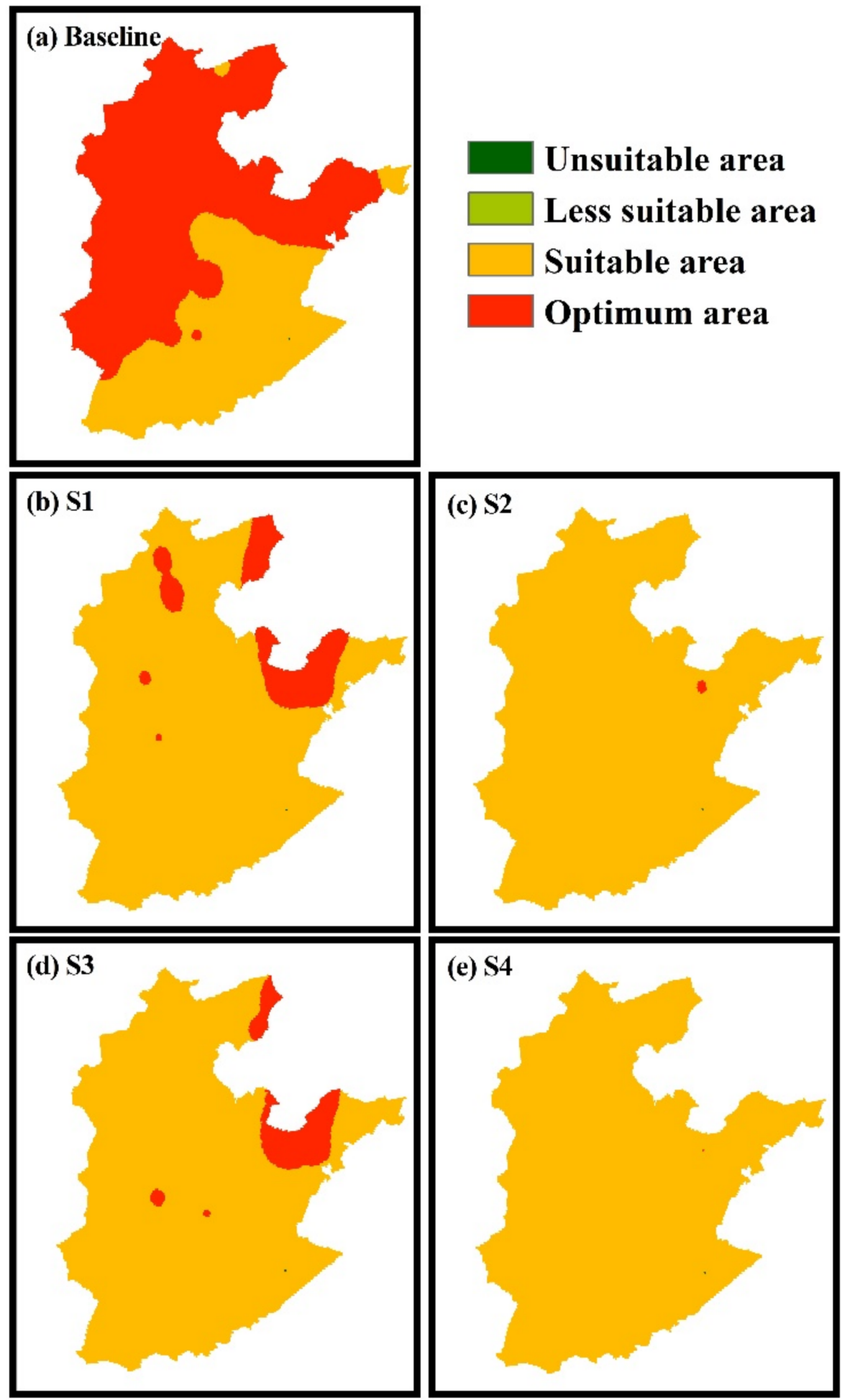

Figure 7. Regional division of climate suitability for maize during the baseline period (1981-2010) (a) and four future scenarios (b-e) in the NCP.

\subsection{Effects of Sowing Date Adjustment on the Climate Suitability of Maize in the NCP}

Adjustment of SD has a significant impact on the phenology of maize, while the FD and MD of maize changed with the adjustment of SD (Figure S3). Moreover, the climate 
suitability was closely related to the growth periods. So there was a significant difference for the climate suitability based on various SDs (Figure 8). The $S_{S}, S_{T}, S_{P}$ and $S_{Z}$ at the VGP declined with the delay of SD under all future scenarios, while the climate suitability went up with the advance of SD (Figure 8a,d,g,j). Additionally, the climate suitability for the RGP increased due to the delay of SD except the $S_{P}$ (Figure 8b,e,h,k). Overall, the delay of SD can effectively increase the climate suitability at the WGP, especially in the S4 (Figure 8c,f,i,l). The adjustment of SD led to the change of maize growth period, while there were great differences in climatic resources at different growth periods of maize. The temporal changes of main climate factors (precipitation, sunshine duration, mean temperature, maximum temperature, minimum temperature) from May to October in the baseline period, S1, S2, S3, and S4, are shown in Figure 9. The climate factors varied greatly from month to month, which contributed to the change of climate suitability for different SDs.
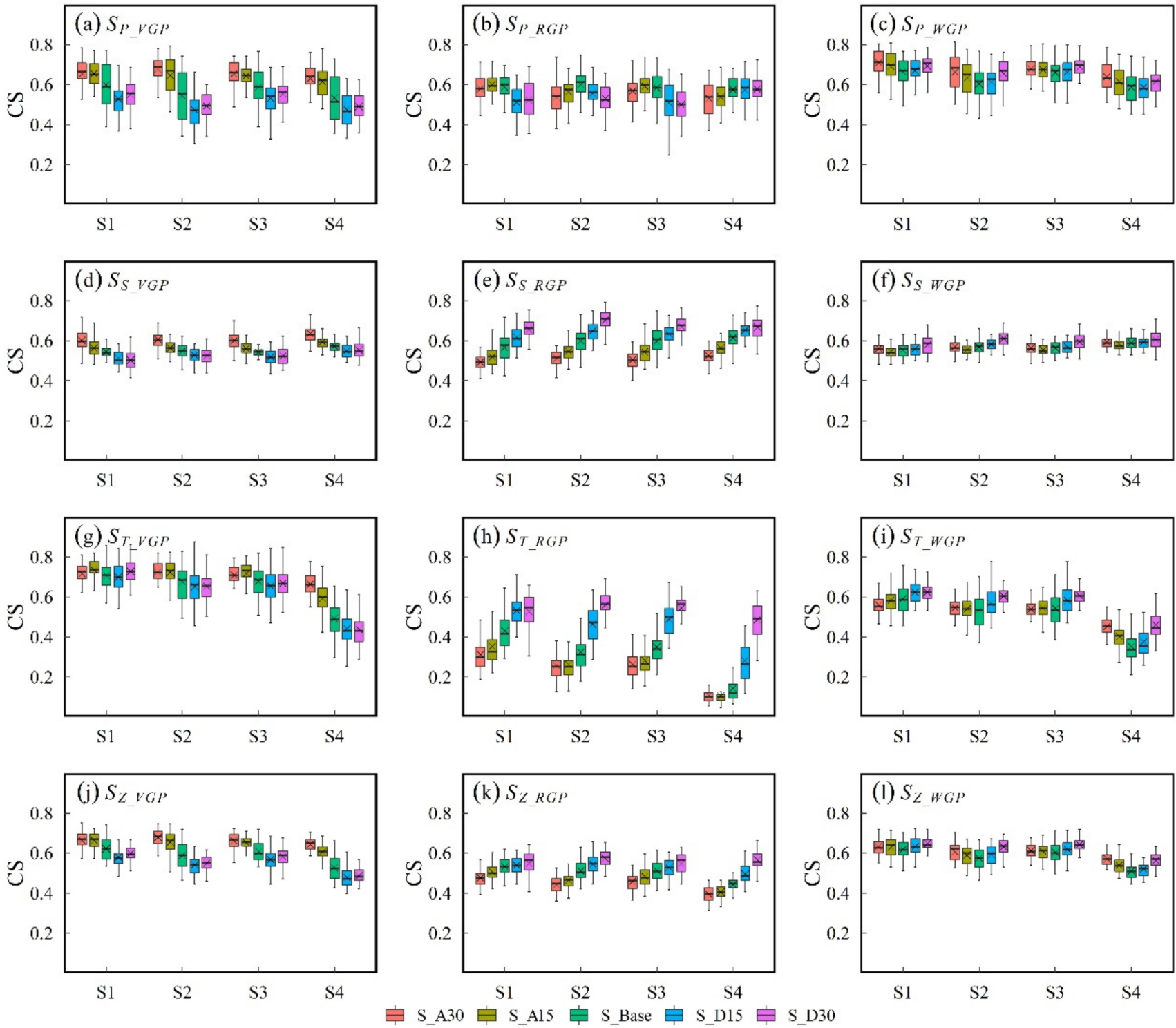

Figure 8. The climate suitability of maize for the vegetative growth period $(\mathbf{a}, \mathbf{d}, \mathbf{g}, \mathbf{j})$, reproductive growth period $(\mathbf{b}, \mathbf{e}, \mathbf{h}, \mathbf{k})$ and whole growth period $(\mathbf{c}, \mathbf{f}, \mathbf{i}, \mathbf{l})$ under different sowing dates in the NCP during the 2040s and 2080s under SSP245 and SSP585 (S1, S2, S3, and S4 are the SSP245_2040s, SSP245_2080s, SSP585_2040s, and SSP585_2080s). 

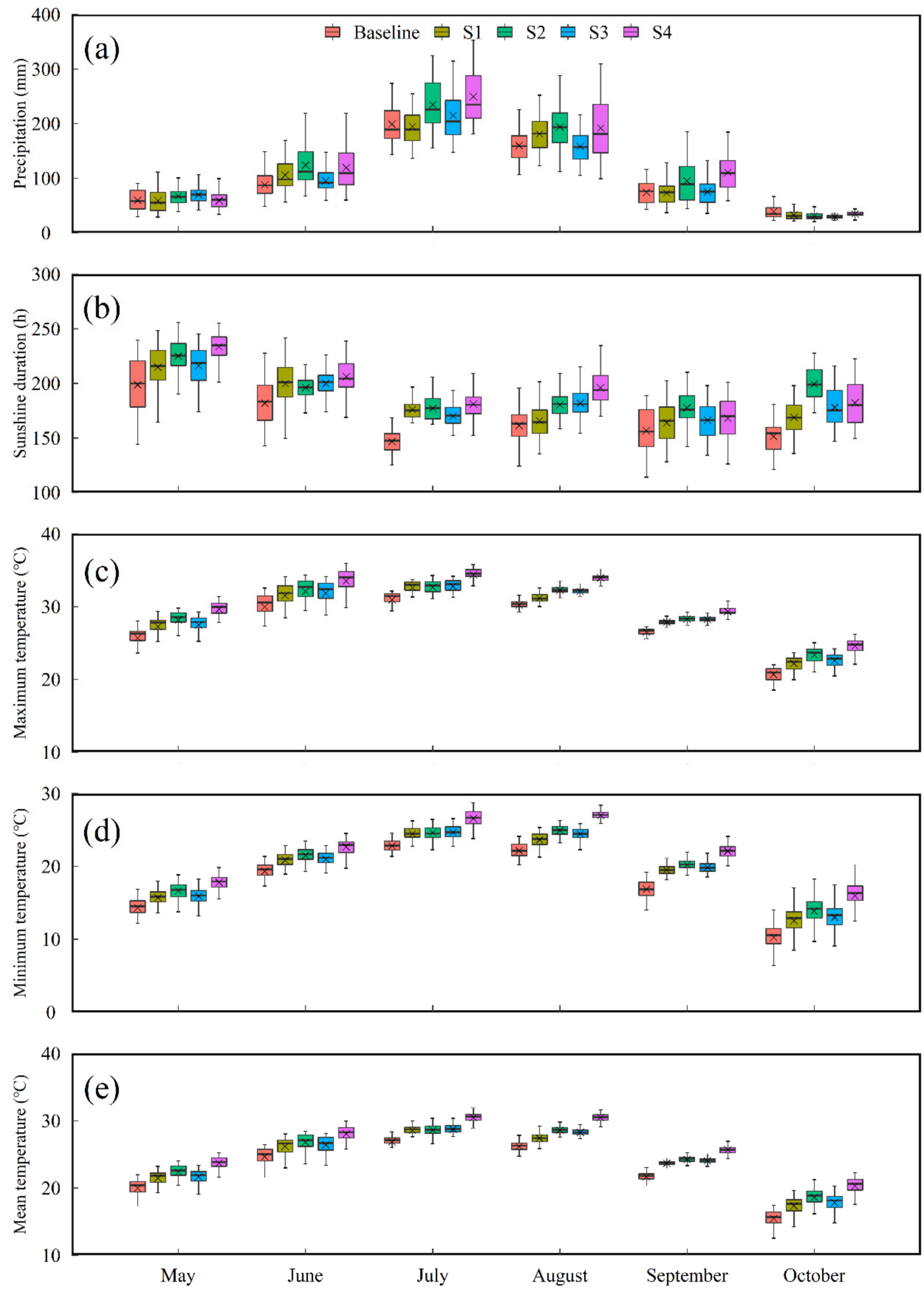

Figure 9. The temporal change of precipitation (a), sunshine duration (b), maximum temperature (c), minimum temperature(d) and, mean temperature (e) from May to October in the North China Plain during the baseline period, the 2040s and 2080s. 


\section{Discussion}

Climate change has a significant impact on the growth process and yield formation of maize in China. In recent decades, climate warming not only brought forward flowering date and maturity date but also shortened RGP and WGP $[46,59,60]$. With future climate change, the phenological period of maize in the future will also change further [61]. In order to study the influence of future climate suitability on maize better, the phenology shift of maize should also be taken into account. The previous study analyzed the spatialtemporal characteristics of maize climate suitability in the future period across the NCP, while the phenology of maize under future scenarios was obtained by calculating the active accumulated temperature [15]. Nevertheless, the process of crop growth is complicated. There is a deficiency of mechanism to determine crop growth period by calculating effective accumulated temperature. Consequently, we used the APSIM model to simulate the flowering date and maturity date of maize. The flowering date and maturity date simulated by the APSIM model under future scenarios in our study present the trend of significant advance across the NCP (Figure S4).

Overall, the $S_{T}$ across the NCP during the baseline period was higher than 0.5 , while the values of $S_{T_{-} V G P}$ and $S_{T_{-} W G P}$ in the north of NCP exceeded 0.7 (Figure $4 \mathrm{~g}-\mathrm{i}$ ). However, the decrease in $S_{T_{-} V G P}, S_{T_{-} R G P}$, and $S_{T_{-} W G P}$ in the future was remarkable, especially the decline of $S_{T_{-} V G P}, S_{T_{-} R G P}$, and $S_{T_{-} W G P}$ under SSP585_2080s was between 0.3 and 0.5 (Figure $3 \mathrm{~g}-\mathrm{i}$ ). This may be largely associated with rising temperature. As shown in Figure $9 \mathrm{c}-\mathrm{e}$, the mean temperature, maximum temperature, and minimum temperature across the NCP will increase markedly under four future scenarios compared to the baseline period. The warm temperatures can improve the growth of crops before the threshold is reached, while yields will abruptly diminish subsequently [62,63]. Furthermore, the sensitivity to extreme temperature changes at different growth stages of crops [64] is particularly significant during the reproductive growth period [65]. The heat stress during the reproductive growth period can affect pollination, reduce male fertility and seed quality, ultimately lead to the loss of kernel weight and yield [65-67]. Our results indicated that $S_{T_{-} R G P}$ was lower than $S_{T_{-} V G P}$ during 1981-2010 across the NCP (Figure 2g-h), while the decrease in $S_{T_{-} R G P}$ was significantly higher than $S_{T_{-} V G P}$ under future scenarios (Figure $3 \mathrm{~g}-\mathrm{h}$ ). The risk of high temperature for summer maize during future periods in the NCP will become an important field of climate change-related research [65].

In order to ensure crop yield, some adaptive agricultural management measures should be taken to counteract the adverse effects of climate change, including variety renovation, adjustment of sowing date, improvement of fertilization and irrigation conditions, and so on $[68,69]$. For example, the renovation of maize varieties delayed the heading date and maturity date and prolonged the whole growth period at more than $90 \%$ of stations in China, while appropriate late sowing can also prolong the whole growth period [5]. These adaptive agricultural management measures offset the impacts of climate change on maize to some extent and further ensured maize yield [5]. In this study, we investigated the climate suitability of maize for different sowing dates in the NCP during the 2040s and 2080s under SSP245 and SSP585 (Figure 8). Compared to the observed SD during the historical period, the $S_{S}, S_{T}, S_{P}$ and $S_{Z}$ for the VGP declined with the delay of SD in the future, while these for the RGP increased due to the delay of SD except the precipitation suitability (Figure $8 \mathrm{a}, \mathrm{b}, \mathrm{d}, \mathrm{e}, \mathrm{g}, \mathrm{h}, \mathrm{j}, \mathrm{k}$ ). On the whole, the delay of SD can effectively increase the climate suitability during the whole growth period of maize (Figure $8 \mathrm{c}, \mathrm{f}, \mathrm{i}, \mathrm{l}$, ). Due to the adjustment of SD, the overall growth process of maize will change. The FD and MD will postpone delaying the SD of maize (Figure S3). The grain filling stage of maize is sensitive to high temperatures. The delay of SD can postpone the grain filling stage to a relatively cool period, which can reduce the heat damage stress on maize to a certain extent $[37,70]$. Our study indicated the temporal changes of main climate factors from May to October during the present period, the 2040s and 2080s, in the NCP. In the future period, the increase in temperature and sunshine hours in September and October will better meet 
the growing demand for sunshine and temperature resources in the late growth period of maize and avoid the invasion of high temperature.

Based on the global climate model (GCM), we can investigate the climate suitability under future scenarios and further deal with the risks of ecological environment protection and social development from climate change. Compared with CMIP5, CMIP6 models have a certain degree of improvement and development in terms of resolution, physical parameterization, experimental design, and simulation computing capability. The simulation of the climate models from CMIP6 was closer to the observed value, while the uncertainty of simulation was smaller and the accuracy of the simulation was higher [26-28]. Taking the study of extreme climate indices as an example, the climate models from CMIP6 had stronger effects on the extreme temperature indices and extreme precipitation indices than the climate models from CMIP5, which can well reproduce the changing trend of the extreme climate indices [71,72]. In our study, the BCC-CSM2-MR model from CMIP6 processed by the statistically downscaled method developed by Liu and Zuo [41] was used to estimate the spatio-temporal variation characteristics of future climate suitability under different climate scenarios. The statistically downscaled method could reproduce the climate statistics at multiple time scales for historical periods and correct the stationary errors effectively [44], while the statistically downscaled data using the method has been applied in previous research $[38,73,74]$.

The study of climate suitability can be used to cope with the impact of climate change on crop production. We can not only make specific divisions of regions based on the climate suitability model [17-20] but also optimize the selection of crop variety [21-23]. We set the regional division of climate suitability for maize in the baseline and future periods according to the statistical principle and referring to the expression of possibility in the IPCC4 (Figure 7a). The regional division of climate suitability during 1981-2010 in the study was close to the results of relevant research [17]. With climate warming, ST and SZ will decrease significantly under four future scenarios, which causes the change in the regional division of climate suitability (Figure $7 \mathrm{~b}-\mathrm{e}$ ). Under four future scenarios, the most area of the optimum area in the NCP will change into the suitable area (Figure $7 \mathrm{~b}-\mathrm{e}$ ). In the future, the adoption of specific adaptations or mitigation measures against the risk of heatwaves needs to be taken seriously [70]. Moreover, there was a certain correlation between climate suitability and climatic yield $[14,15]$. The climate suitability combined with climate information and phenology information can be used as an improved climate index in the yield prediction model to improve the effect of prediction.

\section{Conclusions}

The study of crop climate suitability can enhance the ability to cope with the impact of climate change on crop production. The study developed a climate suitability model of maize and investigated the climate suitability of maize under the historical period and two future periods in the NCP based on the BCC-CSM2-MR model from CMIP6. APSIM model was used to simulate the phenology data of maize under future climate scenarios to improve accuracy and reliability. The results showed that the BCC projections for climate suitability were in suitable consistency with the observations. In 1981-2010, the $S_{P}, S_{T}$, and $S_{Z}$ were high in the north and low in the south. The $S_{P}, S_{T}$, and $S_{Z}$ decreased under all the future climate scenarios in most areas of $\mathrm{NCP}$ while the $S$ s presented an increasing trend. Therefore, the optimum area decreases greatly under four future scenarios in the NCP while the suitable area increases significantly. Moreover, the delay of SD can effectively increase the climate suitability during the whole growth period, especially under the SSP585 scenario in 2071-2100. Thus the adjustment of SD had essential impacts on the climate suitability, which was advantageous to adapt to climate change and promoted agricultural production in the NCP.

Supplementary Materials: The following supporting information can be downloaded at: https: / / www.mdpi.com/article/10.3390/agriculture12030348/s1, Figure S1: The spatial distribution of the 
change of maize climate suitability for the vegetative growth pe-riod $(a, d, g, j)$, reproductive growth period $(b, e, h, k)$ and whole growth period $(\mathrm{c}, \mathrm{f}, \mathrm{i}, \mathrm{l})$ under SSP245 during 2040s compared to the baseline period (1980-2010) in the NCP, Figure S2: The spatial distribution of the change of maize climate suitability for the vegetative growth pe-riod $(a, d, g, j)$, reproductive growth period $(b, e, h, k)$ and whole growth period (c,f,i,l) under SSP245 during 2080s compared to the baseline period (1980-2010) in the NCP, Figure S3: The simulated flowering date (a) and maturity date (b) of maize for different sowing dates in the NCP during 2040s and 2080s under SSP245 and SSP585, Figure S4: The simulated changes of flowering date and maturity date across the North China Plain during 2040s and 2080s under SSP245 and SSP585 compared to the baseline (1981-2010).

Author Contributions: Conceptualization, D.X.; methodology and data analysis, Y.Z.; writing of original draft preparation, Y.Z.; providing the future climate scenario data, D.L.; writing of review and editing, D.X., H.B., J.T. and D.L. All authors have read and agreed to the published version of the manuscript.

Funding: National Natural Science Foundation of China, grant/award number: 41901128.

Institutional Review Board Statement: Not applicable.

Informed Consent Statement: Not applicable.

Data Availability Statement: The climatological data that support the findings of this study during manuscript preparation were available from the corresponding author on reasonable request. The detailed access to the data: The historical records about daily climate data from China's Meteorological Administration (CMA) (http:/ / data.cma.cn/, accessed on 1 February 2020); Future climate scenario data were provided by the World Climate Research Program (WCRP) of Coupled Model Inter-comparison Project phase 6 (CMIP6, https: / / esgf-node.llnl.gov/search/cmip6/ (accessed on 20 February 2020)).

Acknowledgments: We are grateful to the NSW Department of Primary Industries, Australia, for providing the statistically downscaled climate data for the BCC-CSM2-MR model (BCC) from Coupled Model Comparison Program (CMIP6).

Conflicts of Interest: The authors declare no conflict of interest.

\section{References}

1. IPCC. Summary for Policymakers. In Global Warming of $1.5^{\circ} \mathrm{C}$. An IPCC Special Report on the Impacts of Global Warming of $1.5^{\circ} \mathrm{C}$ above Pre-Industrial Levels and Related Global Greenhouse Gas Emission Pathways, in the Context of Strengthening the Global Response to the Threat of Climate Change, Sustainable Development, and Efforts to Eradicate Poverty; IPCC: Geneva, Switzerland, 2018.

2. Lobell, D.B.; Asner, G.P. Climate and management contributions to recent trends in U.S. agricultural yields. Science 2003, $299,1032$. [CrossRef] [PubMed]

3. Lobell, D.B.; Burke, M.B.; Tebaldi, C.; Mastrandrea, M.D.; Falcon, W.P.; Naylor, R.L. Prioritizing climate change adaptation needs for food security in 2030. Science 2008, 319, 607-610. [CrossRef] [PubMed]

4. Tao, F.; Zhang, Z.; Shi, W.; Liu, Y.; Xiao, D.; Zhang, S.; Zhu, Z.; Wang, M.; Liu, F. Single rice growth period was prolonged by cultivars shifts, but yield was damaged by climate change during 1981-2009 in China, and late rice was just opposite. Glob. Chang. Biol. 2013, 19, 3200-3209. [CrossRef] [PubMed]

5. Tao, F.; Zhang, S.; Zhang, Z.; Rotter, R.P. Maize growing duration was prolonged across China in the past three decades under the combined effects of temperature, agronomic management, and cultivar shift. Glob. Chang. Biol. 2014, 20, 3686-3699. [CrossRef]

6. Liu, B.; Asseng, S.; Müller, C.; Ewert, F.; Elliott, J.; Lobell, D.B.; Martre, P.; Ruane, A.C.; Wallach, D.; Jones, J.W.; et al. Similar estimates of temperature impacts on global wheat yield by three independent methods. Nat. Clim. Chang. 2016, 6, 1130-1136. [CrossRef]

7. Fletcher, A.L.; Chen, C.; Ota, N.; Lawes, R.A.; Oliver, Y.M. Has historic climate change affected the spatial distribution of water-limited wheat yield across Western Australia? Clim. Chang. 2020, 159, 347-364. [CrossRef]

8. Ye, Z.; Qiu, X.; Chen, J.; Cammarano, D.; Ge, Z.; Ruane, A.C.; Liu, L.; Tang, L.; Cao, W.; Liu, B.; et al. Impacts of $1.5^{\circ} \mathrm{C}$ and $2.0^{\circ} \mathrm{C}$ global warming above pre-industrial on potential winter wheat production of China. Eur. J. Agron. 2020, 120, 126149. [CrossRef]

9. Salman, S.A.; Shahid, S.; Sharafati, A.; Salem, G.S.A.; Bakar, A.A.; Farooque, A.A.; Chung, E.-S.; Ahmed, Y.A.; Mikhail, B.; Yaseen, Z.M. Projection of Agricultural Water Stress for Climate Change Scenarios: A Regional Case Study of Iraq. Agriculture 2021, 11, 1288. [CrossRef]

10. Mall, R.K.; Lal, M.; Bhatia, V.S.; Rathore, L.S.; Singh, R. Mitigating climate change impact on soybean productivity in India: A simulation study. Agric. For. Meteorol. 2004, 121, 113-125. [CrossRef]

11. Wang, P.; Wu, D.; Yang, J.; Ma, Y.; Feng, R.; Huo, Z. Summer maize growth under different precipitation years in the Huang-HuaiHai Plain of China. Agric. For. Meteorol. 2020, 285-286, 107927. [CrossRef] 
12. Ma, S.Q. The climatic and ecological suitability of central Jilin Province for developing maize zones. J. Ecol. 1990, $54,40-45$.

13. Gong, L.J.; Yang-Hui, J.I.; Wang, P.; Zhu, H.X.; Wang, L.L.; Wang, Q.J. Variation of Climate Suitability of Maize in Northeast of China. J. Maize Sci. 2013, 21, 140-146.

14. Cao, Y.; Qi, J.; Wang, F.; Li, L.; Lu, J. Analysis of climate suitability of spring maize in Liaoning Province based on modulus and mathematics. Sci. Geogr. Sin. 2020, 40, 1210-1220.

15. Tang, X.; Liu, H. Climate suitability for summer maize on the North China Plain under current and future climate scenarios. Int. J. Climatol. 2020, 41, 1-18. [CrossRef]

16. He, Q.; Zhou, G. Climatic suitability of potential summer maize planting zones in China. Acta Geogr. Sin. 2011, 66, 1443-1450.

17. He, Q.; Zhou, G. The climatic suitability for maize cultivation in China. Chin. Sci. Bull. 2012, 57, 395-403. [CrossRef]

18. Sun, J.; Zhou, G.; Sui, X. Climatic suitability of the distribution of the winter wheat cultivation zone in China. Eur. J. Agron. 2012, $43,77-86$.

19. Irimia, L.M.; Patriche, C.V.; Quenol, H.; Sfîcă, L.; Foss, C. Shifts in climate suitability for wine production as a result of climate change in a temperate climate wine region of Romania. Theor. Appl. Climatol. 2017, 131, 1069-1081. [CrossRef]

20. He, Q.; Zhou, G.; Lü, X.; Zhou, M. Climatic suitability and spatial distribution for summer maize cultivation in China at 1.5 and $2.0^{\circ} \mathrm{C}$ global warming. Sci. Bull. 2019, 64, 690-697. [CrossRef]

21. He, Y.; Yao, Y.; Tang, H.; Chen, Y.; Li, J.; Yang, P.; Chen, Z.; Xin, X.; Wang, L.; Li, D.; et al. Using an Integrated Response-Function Method to Explore Agro-Climatic Suitability for Spring Soybean Growth in North China. J. Appl. Meteorol. Climatol. 2011, 50, 1354-1361. [CrossRef]

22. Holzkämper, A.; Calanca, P.; Fuhrer, J. Identifying climatic limitations to grain maize yield potentials using a suitability evaluation approach. Agric. For. Meteorol. 2013, 168, 149-159. [CrossRef]

23. Zhao, J.; Guo, J.; Xu, Y.; Mu, J. Effects of climate change on cultivation patterns of spring maize and its climatic suitability in Northeast China. Agric. Ecosyst. Environ. 2015, 202, 178-187. [CrossRef]

24. Ding, Y.; Wang, H. Newly acquired knowledge on the scientific issues related to climate change over the recent 100 years in China. Chin. Sci. Bull. 2015, 61, 1029-1041. [CrossRef]

25. Zhou, T.J.; Zou, L.W.; Chen, X.L. Commentary on the Coupled Model Intercomparison Project Phase 6 (CMIP6). Clim. Chang. Res. 2019, 15, 445-456.

26. Fu, Y.; Lin, Z.; Guo, D. Improvement of the simulation of the summer East Asian westerly jet from CMIP5 to CMIP6. Atmos. Ocean. Sci. Lett. 2020, 13, 550-558. [CrossRef]

27. Kim, Y.-H.; Min, S.-K.; Zhang, X.; Sillmann, J.; Sandstad, M. Evaluation of the CMIP6 multi-model ensemble for climate extreme indices. Weather Clim. Extrem. 2020, 29, 100269. [CrossRef]

28. Chen, H.; Sun, J.; Lin, W.; Xu, H. Comparison of CMIP6 and CMIP5 models in simulating climate extremes. Sci. Bull. 2020, 65, 1415-1418. [CrossRef]

29. Wu, T.; Lu, Y.; Fang, Y.; Xin, X.; Li, L.; Li, W.; Jie, W.; Zhang, J.; Liu, Y.; Zhang, L.; et al. The Beijing Climate Center Climate System Model (BCC-CSM): Main Progress from CMIP5 to CMIP6. Geosci. Model Dev. Discuss. 2018, 12, 1573-1600. [CrossRef]

30. Xin, X.G.; Wu, T.; Zhang, J.; Zhang, F.; Wei-Ping, L.I.; Zhang, Y.W.; Yi-Xiong, L.U.; Fang, Y.J.; Jie, W.H.; Zhang, L. Introduction of BCC models and its participation in CMIP6. Clim. Chang. Res. 2019, 15, 533-539.

31. Sang, Y.; Ren, H.-L.; Shi, X.; Xu, X.; Chen, H. Improvement of Soil Moisture Simulation in Eurasia by the Beijing Climate Center Climate System Model from CMIP5 to CMIP6. Adv. Atmos. Sci. 2020, 38, 237-252. [CrossRef]

32. Haarhoff, S.J.; Swanepoel, P.A. Plant Population and Maize Grain Yield: A Global Systematic Review of Rainfed Trials. Crop Sci. 2018, 58, 1819-1829. [CrossRef]

33. Zhao, Y.; Xiao, D.; Bai, H.; Tao, F. Research progress on the response and adaptation of crop phenology to climate change in China. Prog. Geogr. 2019, 38, 224-235.

34. National Bureau of Statistics of China. China Rural Statistical Yearbook; China Statistics Press: Beijing, China, 2018.

35. Huang, S.; Lv, L.; Zhu, J.; Li, Y.; Tao, H.; Wang, P. Extending growing period is limited to offsetting negative effects of climate changes on maize yield in the North China Plain. Field Crops Res. 2018, 215, 66-73. [CrossRef]

36. Xiao, D.; Tao, F. Contributions of cultivar shift, management practice and climate change to maize yield in North China Plain in 1981-2009. Int. J. Biometeorol. 2016, 60, 1111-1122. [CrossRef] [PubMed]

37. Xiao, D.; Liu, D.L.; Wang, B.; Feng, P.; Waters, C. Designing high-yielding maize ideotypes to adapt changing climate in the North China Plain. Agric. Syst. 2020, 181, 102805. [CrossRef]

38. Bai, H.; Xiao, D.; Wang, B.; Liu, D.L.; Feng, P.; Tang, J. Multi-model ensemble of CMIP6 projections for future extreme climate stress on wheat in the North China plain. Int. J. Climatol. 2020, 41, 1-16. [CrossRef]

39. Xiao, D.; Liu, D.L.; Wang, B.; Feng, P.; Bai, H.; Tang, J. Climate change impact on yields and water use of wheat and maize in the North China Plain under future climate change scenarios. Agric. Water Manag. 2020, 238, 106238. [CrossRef]

40. O’Neill, B.C.; Tebaldi, C.; van Vuuren, D.P.; Eyring, V.; Friedlingstein, P.; Hurtt, G.; Knutti, R.; Kriegler, E.; Lamarque, J.-F.; Lowe, J.; et al. The Scenario Model Intercomparison Project (ScenarioMIP) for CMIP6. Geosci. Model Dev. 2016, 9, $3461-3482$. [CrossRef]

41. Liu, D.L.; Zuo, H. Statistical downscaling of daily climate variables for climate change impact assessment over New South Wales, Australia. Clim. Chang. 2012, 115, 629-666. [CrossRef] 
42. Richardson, C.; Wright, D. WGEN: A Model for Generating Daily Weather Variables; USA Department of Agriculture, Agricultural Research Service: Springfield, VA, USA, 1984; Volume ARS-8.

43. Asseng, S.; Keating, B.A.; Fillery, I.R.P.; Gregory, P.J.; Abrecht, D.G. Performance of the APSIM-wheat model in Western Australia Field Crops Res. 1998, 57, 163-179. [CrossRef]

44. Asseng, S.; Keulen; Stol, W. Performance and application of the APSIM Nwheat model in the Netherlands. Eur. J. Agron. 2000, 12, 37-54. [CrossRef]

45. Keating, B.A.; Carberry, P.S.; Hammer, G.L.; Probert, M.E.; Robertson, M.J.; Holzworth, D.; Huth, N.I.; Hargreaves, J.N.G.; Meinke, H.; Hochman, Z. An overview of APSIM, a model designed for farming systems simulation. Eur. J. Agron. 2003, 18, 267-288. [CrossRef]

46. Xiao, D.; Qi, Y.; Shen, Y.; Tao, F.; Moiwo, J.P.; Liu, J.; Wang, R.; Zhang, H.; Liu, F. Impact of warming climate and cultivar change on maize phenology in the last three decades in North China Plain. Theor. Appl. Climatol. 2016, 124, 653-661. [CrossRef]

47. Teixeira, E.I.; Brown, H.E.; Michel, A.; Meenken, E.; Hu, W.; Thomas, S.; Huth, N.I.; Holzworth, D.P. Field estimation of water extraction coefficients with APSIM-Slurp for water uptake assessments in perennial forages. Field Crops Res. 2018, 222, 26-38. [CrossRef]

48. Arshad, A.; Raza, M.A.; Zhang, Y.; Zhang, L.; Wang, X.; Ahmed, M.; Habib-ur-Rehman, M. Impact of Climate Warming on Cotton Growth and Yields in China and Pakistan: A Regional Perspective. Agriculture 2021, 11, 97. [CrossRef]

49. Xiao, D.; Bai, H.; Liu, D.L.; Tang, J.; Wang, B.; Shen, Y.; Cao, J.; Feng, P. Projecting future changes in extreme climate for maize production in the North China Plain and the role of adjusting sowing date. Mitig. Adapt. Strateg. Glob. Chang. 2022, $27,21$. [CrossRef]

50. Pu, J.Y.; Yao, X.Y.; Yao, R.X. Variations of summer and autumn grain crops' climatic suitability in the areas east of Yellow River in Gansu in recent 40 years. Agric. Res. Arid. Areas 2011, 29, 253-258.

51. Hou, Y.Y.; Zhang, Y.H.; Wang, L.Y.; Hou-Quan, L.; Song, Y.B. Climatic suitability model for spring maize in Northeast China. Chin. J. Appl. Ecol. 2013, 24, 3207-3212.

52. Zhao, Y.; Xiao, D.; Bai, H.; Tang, J.Z. Climatic suitability degrees of winter wheat and summer maize in the North China Plain Chin. J. Ecol. 2020, 39, 1-12.

53. Zhao, F.; Qian, H.S.; Jiao, S.X. The climatic suitability model of crop: A case study of winter wheat in Henan province. Resour. Sci. $2003,25,77-82$.

54. Huang, H. A study on the climatic ecology adaptability of the crop production in the red and yellow soils region of China J. Nat. Resour. 1996, 11, 340-346.

55. Xu, L.; Lv, H.; Fang, L. Effect of Climate Change on the Climate Suitability of Summer Maize on the Huang-Huai-Hai Plain. Resour. Sci. 2014, 36, 0782-0787.

56. Wang, E.; Han, X. The productivity evaluation and its application of winter wheat and summer maize in Huang-Huai-Hai region. Chin. J. Agrometeorol. 1990, 11, 41-46.

57. Allen, R.; Pereira, L.; Dirk, R.; Smith, M. Crop Evapotranspiration Guidelines for Computing Crop Water Requirements; FAO Irrigation and Drainage Paper, No. 56; FAO_Food and Agriculture Organization of the United Nations: Rome, Italy, 1998; Volume 300, pp. 53-62.

58. Wang, L.X.; Ren, Z.Y. Appraisal and analysis of agriculture eco-climatic amenity in Datong city of Shanxi province. Geogr. Res. 2007, 11, 319-324

59. Wang, Z.; Chen, J.; Li, Y.; Li, C.; Zhang, L.; Chen, F. Effects of climate change and cultivar on summer maize phenology. Int. J. Plant Prod. 2016, 10, 509-526.

60. Xiao, D.; Zhao, Y.; Bai, H.; Hu, Y.; Cao, J. Impacts of climate warming and crop management on maize phenology in northern China. J. Arid. Land 2019, 11, 892-903. [CrossRef]

61. Xiao, D.; Bai, H.; Liu, D. Impact of Future Climate Change on Wheat Production: A Simulated Case for China's Wheat System Sustainability 2018, 10, 1277. [CrossRef]

62. Lobell, D.B.; Roberts, M.J.; Schlenker, W.; Braun, N.; Little, B.B.; Rejesus, R.M.; Hammer, G.L. Greater sensitivity to drought accompanies maize yield increase in the U.S. Midwest. Science 2014, 344, 516-519. [CrossRef]

63. Zhao, C.; Liu, B.; Piao, S.; Wang, X.; Lobell, D.B.; Huang, Y.; Huang, M.; Yao, Y.; Bassu, S.; Ciais, P.; et al. Temperature increase reduces global yields of major crops in four independent estimates. Proc. Natl. Acad. Sci. USA 2017, 114, 9326-9331. [CrossRef]

64. Bailey-Serres, J.; Parker, J.E.; Ainsworth, E.A.; Oldroyd, G.E.D.; Schroeder, J.I. Genetic strategies for improving crop yields. Nature 2019, 575, 109-118. [CrossRef]

65. Bita, C.E.; Gerats, T. Plant tolerance to high temperature in a changing environment: Scientific fundamentals and production of heat stress-tolerant crops. Front. Plant Sci. 2013, 4, 273. [CrossRef] [PubMed]

66. Wang, N.; Wang, E.; Wang, J.; Zhang, J.; Zheng, B.; Huang, Y.; Tan, M. Modelling maize phenology, biomass growth and yield under contrasting temperature conditions. Agric. For. Meteorol. 2018, 250-251, 319-329. [CrossRef]

67. Siddik, M.A.; Zhang, J.; Chen, J.; Qian, H.; Jiang, Y.; Raheem, A.K.; Deng, A.; Song, Z.; Zheng, C.; Zhang, W. Responses of indica rice yield and quality to extreme high and low temperatures during the reproductive period. Eur. J. Agron. 2019, 106, 30-38. [CrossRef]

68. Owusu Danquah, E.; Beletse, Y.; Stirzaker, R.; Smith, C.; Yeboah, S.; Oteng-Darko, P.; Frimpong, F.; Ennin, S.A. Monitoring and Modelling Analysis of Maize (Zea mays L.) Yield Gap in Smallholder Farming in Ghana. Agriculture 2020, 10, 420. [CrossRef] 
69. Zhai, L.; Zhang, L.; Yao, H.; Zheng, M.; Ming, B.; Xie, R.; Zhang, J.; Jia, X.; Ji, J. The Optimal Cultivar $\times$ Sowing Date $\times$ Plant Density for Grain Yield and Resource Use Efficiency of Summer Maize in the Northern Huang-Huai-Hai Plain of China. Agriculture 2021, 12, 7. [CrossRef]

70. Lv, Z.; Li, F.; Lu, G. Adjusting sowing date and cultivar shift improve maize adaption to climate change in China. Mitig. Adapt. Strateg. Glob. Chang. 2020, 25, 87-106. [CrossRef]

71. Lin, W.; Chen, H. Assessment of model performance of precipitation extremes over the mid-high latitude areas of Northern Hemisphere: From CMIP5 to CMIP6. Atmos. Ocean. Sci. Lett. 2020, 13, 598-603. [CrossRef]

72. Luo, N.; Guo, Y.; Gao, Z.B.; Chen, K.; Chou, J. Assessment of CMIP6 and CMIP5 model performance for extreme temperature in China. Atmos. Ocean. Sci. Lett. 2020, 13, 589-597. [CrossRef]

73. Wang, B.; Liu, D.L.; Macadam, I.; Alexander, L.V.; Abramowitz, G.; Yu, Q. Multi-model ensemble projections of future extreme temperature change using a statistical downscaling method in south eastern Australia. Clim. Chang. 2016, 138, 85-98. [CrossRef]

74. Wang, B.; Feng, P.; Li Liu, D.; O’Leary, G.J.; Macadam, I.; Waters, C.; Asseng, S.; Cowie, A.; Jiang, T.; Xiao, D. Sources of uncertainty for wheat yield projections under future climate are site-specific. Nat. Food 2020, 1, 720-728. [CrossRef] 